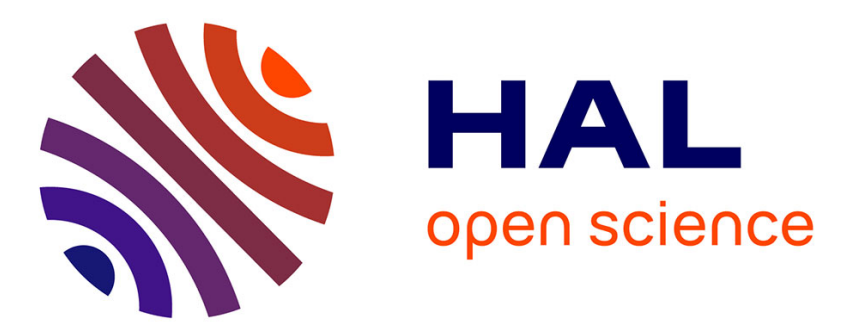

\title{
Clinical and neurocognitive issues associated with Bosch-Boonstra-Schaaf optic atrophy syndrome: A case study
}

Erin K Bojanek, Matthew W Mosconi, Stephen J. Guter, Catalina Betancur, Carol Macmillan, Edwin H. Cook

\section{To cite this version:}

Erin K Bojanek, Matthew W Mosconi, Stephen J. Guter, Catalina Betancur, Carol Macmillan, et al.. Clinical and neurocognitive issues associated with Bosch-Boonstra-Schaaf optic atrophy syndrome: A case study. American Journal of Medical Genetics Part A, 2019, 182 (1), pp.213-218. 10.1002/ajmg.a.61409 . inserm-02479951

\section{HAL Id: inserm-02479951 https://www.hal.inserm.fr/inserm-02479951}

Submitted on 14 Feb 2020

HAL is a multi-disciplinary open access archive for the deposit and dissemination of scientific research documents, whether they are published or not. The documents may come from teaching and research institutions in France or abroad, or from public or private research centers.
L'archive ouverte pluridisciplinaire HAL, est destinée au dépôt et à la diffusion de documents scientifiques de niveau recherche, publiés ou non, émanant des établissements d'enseignement et de recherche français ou étrangers, des laboratoires publics ou privés. 


\title{
Clinical and neurocognitive issues associated with Bosch-Boonstra-Schaaf optic atrophy syndrome: A case study
}

Erin K. Bojanek ${ }^{1,2}$, Matthew W. Mosconi ${ }^{1,2}$, Stephen Guter $^{3}$, Catalina Betancur ${ }^{4}$, Carol Macmillan ${ }^{5}$, Edwin H. Cook ${ }^{3}$

${ }^{1}$ Schiefelbusch Institute for Life Span Studies and Clinical Child Psychology Program, University of Kansas, Lawrence, Kansas

${ }^{2}$ Kansas Center for Autism Research and Training (K-CART), University of Kansas Medical Center, Overland Park, Kansas

${ }^{3}$ Institute for Juvenile Research, University of Illinois at Chicago, Chicago, Illinois

${ }^{4}$ Sorbonne Université, INSERM, CNRS, Neuroscience Paris Seine, Institut de Biologie Paris Seine, Paris, France

${ }^{5}$ Department of Pediatrics, University of Chicago, Chicago, Illinois

\section{Funding information}

Eunice Kennedy Shriver National Institute of Child Health and Human Development, Grant/ Award Number: U54 HD090216-01; National Institute of Child Health and Human Development, Grant/Award Number: P50HD055751; National Institute of Mental Health, Grant/Award Numbers: K23 MH092696-05, R01 MH112734-01; National Institutes of Health, Grant/Award Numbers: HHSN268201200008I, X01 HG007235

\begin{abstract}
Nuclear receptor subfamily 2 group $\mathrm{F}$ member 1 (NR2F1) is an orphan receptor and transcriptional regulator that is involved in neurogenesis, visual processing and development, and cortical patterning. Alterations in NR2F1 cause Bosch-Boonstra-Schaaf optic atrophy syndrome (BBSOAS), a recently described autosomal dominant disorder characterized by intellectual and developmental disabilities and optic atrophy. This study describes the clinical and neurocognitive features of an individual with a de novo nonsense variant in NR2F1 (NM_005654.5:c.82C > T, p.Gln28*), identified by whole exome sequencing. The patient was diagnosed with autism spectrum disorder (ASD) and unlike most previously reported cases, he had no developmental delay, superior verbal abilities (verbal IQ = 141), and high educational attainment despite reduced non-verbal abilities (nonverbal IQ $=63$ ). He had optic nerve hypoplasia with minimal visual impairment as well as mild dysmorphic features. Compared to both agematched individuals with ASD and healthy controls, the patient showed reductions in manual motor speed, accuracy of saccadic eye movements, and rates of successful behavioral response inhibition. Although the majority of previously reported cases of BBSOAS have been associated with more global intellectual dysfunction, we report on a patient with selective disruption of nonverbal abilities and superior verbal abilities.
\end{abstract}

Keywords: autism, Bosch-Boonstra-Schaaf optic atrophy syndrome, cognitive discrepancy, NR2F1 


\section{INTRODUCTION}

Nuclear receptor subfamily 2 group $F$ member 1 (NR2F1), also known as chicken ovalbumin upstream promotor-transcription factor I (COUP-TFI) in mice, is a highly conserved orphan receptor protein in the steroid/thyroid hormone receptor family that regulates transcription (Bosch et al., 2014; Zhou et al., 1999). NR2F1 has two functional domains, a DNA-binding domain and a ligand-binding domain; the ligand remains unknown (Lin, Qin, Tang, Tsai, \& Tsai, 2011). The functions of NR2F1 have been extensively studied in mice, though studies of patients are sparse. In mice, COUP-TFI plays important roles in neurogenesis (Zhou et al., 1999), visual processing and development (Tang et al., 2010), and cortical patterning (Armentano et al., 2007).

In humans, alterations in NR2F1 cause Bosch-Boonstra-Schaaf optic atrophy syndrome (BBSOAS), an autosomal dominant disorder characterized by visual impairment and optic atrophy, developmental delay and intellectual disability, hypotonia, corpus callosum thinning, and seizures (Bosch et al., 2014; Chen et al., 2016). Autism spectrum disorder (ASD) has been reported in $35 \%$ of affected individuals, and obsessive-compulsive disorder and attention deficit-hyperactivity disorder (ADHD) also have been documented (Chen et al., 2016).

In this report, we describe a 23-year-old male with ASD and a de novo nonsense variant in NR2F1 (c.82C>T, p.Gln28*). We completed a detailed genetic, clinical, and neurocognitive evaluation of this patient including an assessment of sensorimotor and neuropsychological functioning. We also compared the patient's functioning to age-matched individuals with ASD and controls. This report provides one of the best characterized BBSOAS patients to date and expands on the clinical features associated with alterations in NR2F1 and BBSOAS by reporting selective disturbance of nonverbal abilities and superior verbal abilities.

\section{METHODS}

\section{Editorial policies and ethical considerations}

All study procedures were approved by the local Institutional Review Board of the University of Illinois at Chicago. All participants provided written consent to participate.

\section{Participants}

The patient was 23 years old at the time of testing and was examined as part of ongoing Autism Center of Excellence studies at the University of Illinois at Chicago. Six individuals (five males) with ASD and six controls (three males) matched on age (range: 20-29 years-old) and full-scale IQ also were examined (Table 1). For ASD participants, a diagnosis was established according to the Diagnostic and Statistical Manual of Mental Disorders, Fourth Edition, Text Revision (DSM-IV-TR; American Psychiatric Association, 2000) criteria, and based on the Autism Diagnostic Observation Schedule, Second Edition (ADOS-2; Lord et al., 2012) and the Autism Diagnostic Interview-Revised (ADI-R; Rutter, Le Couteur, \& Lord, 2003). No 
parents were available to complete the ADI-R for one participant with ASD. Control participants scored $<8$ on the Social Communication Questionnaire (Rutter, Bailey, \& Lord, 2003) and were excluded for any individual or family history of psychiatric disorders or ASD.

\section{Genetic characterization}

As part of the study, participants underwent copy number variant analysis using Illumina $1 \mathrm{M}$ or 5M SNP microarrays. ASD participants and parents also were exome sequenced and analyzed as described previously (Chen et al., 2017). Clinical confirmation of the NR2F1 mutation was performed in the University of Chicago Genetic Services Laboratory by PCR amplification of exon one and Sanger sequencing in both forward and reverse directions.

\section{Developmental/medical assessment}

A detailed clinical evaluation was completed for the patient including medical history, psychiatric, ophthalmological, and physical evaluations. Medical records also were reviewed.

\section{Intellectual functioning and diagnostic evaluation}

Caregivers of the patient, four participants with ASD, and two controls completed the Aberrant Behavior Checklist to assess hyperactivity, irritability, lethargy, and stereotypy (Aman, Singh, Stewart, \& Field, 1985). Caregivers of the patient and four participants with ASD completed the Vineland Adaptive Behavior Scales to assess adaptive functioning (Sparrow, Chiccetti, \& Balla, 2005). To estimate cognitive abilities, the patient was administered the Wechsler Adult Intelligence Scale, Fourth Edition (WAIS IV; Wechsler, Coalson, \& Raiford, 2008; patient previously completed separate IQ tests) while all other participants were administered the Wechsler Abbreviated Scales of Intelligence (WASI; Wechsler, 1999; Table 1). At the most recent time point, the patient was administered the Wechsler Adult Intelligence Scale, Fourth Edition (WAIS IV; Wechsler, Coalson, \& Raiford, 2008) while all other partici- pants were administered the Wechsler Abbreviated Scales of Intelli- gence (WASI; Wechsler, 1999; Table 1). At age 23, the patient also completed the California Verbal Learning Test-Second Edition (CVLT-II; Delis, Kramer, Kaplan, \& Ober, 2000) and the Brief Visual Spatial Mem- ory Test-Revised (BVMT-R; Benedict, 1997) to assess his verbal and visual memory, respectively.

\section{Neurocognitive Function}

\section{Sensorimotor behavior}

To assess basic sensorimotor processes, a visually guided saccade test was administered in which participants fixated on a central cue, and targets were presented at $\pm 12^{\circ}$ of center (Mosconi et al., 2009). Saccade latency and gain (saccade amplitude: target amplitude) were examined.

In order to assess participants' ability to inhibit prepotent movements, gap and overlap conditions of an antisaccade task were administered, as previously reported (Mosconi et al., 2009). Participants 
fixated on a central target before a peripheral target appeared. They were instructed to inhibit their saccade and look in the mirror location. Saccade latencies and percent of trials where participants looked toward the target (prosaccade errors) were measured.

Oculomotor and manual motor stop-signal tests (SST) also were administered to assess participants' ability to inhibit prepotent responses during conditions in which the target response was not predictable. SST procedures have been reported previously (Schmitt, Ankeny, Sweeney, \& Mosconi, 2016). Briefly, each SST consisted of GO and STOP trials. During GO trials, participants fixated on a central cross-hair and were instructed to respond as quickly as possible when a peripheral target appeared. During STOP trials, a central stop-signal was presented after the target and participants were instructed not to respond. The percentage of accurate STOP trials and GO trial reaction times were examined. Participants completed a baseline task including only GO trials prior to each SST to assess how much they delayed their GO trial responses during the SST. The change in reaction time from baseline to SST GO trials was examined.

\section{Neuropsychological function}

Trails A and B were administered to assess visuomotor planning and cognitive flexibility (Reitan, 1992), respectively. Finger tapping was administered to measure bilateral gross motor speed (Baron, 2003), and the grooved pegboard test was administered to assess fine motor planning and speed (Trites, 1989). Additionally, handedness was measured using the Annett Handedness Questionnaire (Annett, 2004).

\section{RESULTS}

\section{Genetic characterization}

Exome sequencing identified a de novo heterozygous nonsense variant in NR2F1, chr5(GRCh37):g.92920811C>T, NM_005654.5:c.82C>T, p.Gln28*, in the patient, not present in either parent (Chen et al., 2017). This variant is predicted to result in a premature stop codon with nonsensemediated decay and/or protein truncation. The variant was confirmed by targeted sequencing analysis. No clinically relevant copy number variants were identified in the patient.

\section{Developmental/medical assessment}

The patient was born full-term weighing $3.7 \mathrm{~kg}$. He had hyperbilirubinemia treated with phototherapy. At 24 months, hand flapping and toe walking were noted. While in preschool, he received speech therapy for poor articulation and occupational therapy for fine motor skill delays with hypotonia. At age three, he was diagnosed with pervasive developmental disorder-not otherwise specified and ADHD; at age eight he was diagnosed with a nonverbal learning disability; and at age 23 he was diagnosed with ASD after being enrolled in this study. The patient met diagnostic criteria for ASD on the ADOS-2 but not the ADI-R (Table 1) and had a consensus diagnosis of ASD based on DSM-IV-TR criteria. 
At age eight, EEG showed evidence of rare isolated sharp waves arising from central regions. At age 12, EEG revealed a single sharp wave arising from the left central region and a brain MRI was normal. He had cosmetic otoplasty at age 12 for prominent ears, and micrognathia was corrected by jaw expansion surgery at age 15 . At age 23 , his head circumference was $56 \mathrm{~cm}$ ( $31^{\text {st }}$ percentile), height was $171 \mathrm{~cm}\left(29^{\text {th }}\right.$ percentile), and weight was $55.6 \mathrm{~kg}$ (fourth percentile). His physical exam revealed bilateral ear cupping, midface hypoplasia, a flat nasal tip, prominent lips, and generalized joint hyperextensibility.

At age 30, the NR2F1 mutation was confirmed and an MRI showed decreased size of the right optic nerve intraocular segment. Evaluation by a neuro-ophthalmologist showed that both optic nerves otherwise were normal in size, supporting a diagnosis of optic nerve hypoplasia. Retinal nerve fiber layer optical coherence tomography revealed retinal nerve fiber layer thinning in both eyes. The patient has 20/30 vision with glasses and no nystagmus.

\section{Intellectual functioning and diagnostic evaluation}

The patient graduated from college with a double major in history and political science and has had competitive employment. He lives alone with support but does not drive because he is unable to process the visual information, despite his corrected to normal vision. The patient has had a significantly higher verbal IQ than nonverbal IQ across all cognitive assessments with a difference ranging from three to five standard deviations. At the most recent assessment, he had a 5.2 standard deviation discrepancy between his verbal IQ (141) and nonverbal IQ (63) (Table 1). On the memory assessments, the patient showed average verbal memory abilities on the CVLT-II but moderate to severe impairments of visual memory across delayed recall and recognition trials on the BVMT-R. On the Vineland Adaptive Behavior Scales, the patient showed deficits in daily living skills but communication skills in the average range. Standardized neuropsychological measures of motor ability indicated that the patient showed reduced motor speed relative to controls and ASD participants (Table S1).

\section{Neurocognitive function}

During the visually guided saccade task, the patient showed similar latencies and reduced saccade accuracy compared to controls. During the antisaccade task, the patient had similar latencies to controls but more prosaccade errors than both the control and ASD groups, on gap and overlap conditions. During oculomotor and manual motor stop-signal tests, the patient showed reduced stopping accuracy and reaction time slowing compared to both groups (Table 2).

\section{DISCUSSION}

We document a unique clinical profile characterized by superior verbal and impaired nonverbal abilities, optic nerve hypoplasia with minimal visual impairment, ASD, mild dysmorphic features, reduced sensorimotor precision and speed, and executive dysfunction in a patient with a de novo nonsense variant in NR2F1 (p.GIn28*), occurring before the DNA- and ligand-binding domains. This sequence 
change is predicted to result in an abnormal transcript, which may be degraded or lead to the production of a truncated NR2F1 protein. The majority of the previously reported individuals with NR2F1 haploinsufficiency had global developmental delays and intellectual disability. However, one patient with a whole gene deletion was reported to have normal intelligence and also a higher verbal IQ (96) than nonverbal IQ (70) (Bosch et al., 2014; Chen et al., 2016), while a boy with a nonsense variant (p.Tyr171*) was reported with borderline intellectual disability (IQ ca. 77-80; Park et al., 2019). Although few reports have provided a detailed cognitive evaluation, these findings are consistent with the observation that patients with deletions or truncating variants have generally milder phenotypes than those with missense variants in the DNA binding domain (Chen et al., 2016). Indeed, missense variants in the DNA binding domain completely abolish transcriptional activity and may exert a dominant negative effect, given that NR2F1 binds to DNA in the form of dimers (Chen et al., 2016).

The magnitude of the disparity between the patient's verbal and nonverbal abilities was consistent since age 3 years, with a verbal-nonverbal IQ difference ranging from three to five standard deviations as well as significantly impaired visual memory but intact verbal memory. This large split between verbal and nonverbal abilities is extremely rare and in contrast with reports showing a relative weakness in verbal abilities in ASD (Shah \& Frith, 1993). The patient's nonverbal abilities are consistent with studies documenting diagnoses of intellectual disability in patients with BBSOAS (Bosch et al., 2014). Impairments in nonverbal abilities also implicate dysfunctions of thalamocortical circuits. In mouse models, deficits in COUP-TFI lead to improper guidance of thalamocortical axons due to changes in cortical patterning resulting in atypical sensory processing (Armentano et al., 2007; Zhou et al., 1999). Our results suggest that thalamic connections within parietal and occipital cortices may contribute to reduced visuospatial ability, consistent with cerebral visual impairments and elevated rates of optic nerve hypoplasia in BBSOAS (Bosch et al., 2014; Chen et al., 2016). Deficits in nonverbal processing also may result from the patient's optic nerve hypoplasia (Bertacchi, Parisot, \& Studer, 2019), though he did not show visual impairment, as seen in other reported BBSOAS cases (Chen et al., 2016). These findings are consistent with a study of heterozygous Nr2f1 deficient mice that show deficits in learning and processing visual information despite relatively unaffected visual acuity and general cognitive function (Bertacchi et al., 2019). Nr2f1 haploinsufficiency in mice led to defective optic nerve myelination and increased astrogliosis, resulting in slower optic axonal conduction velocity from the retina to higher level visual processing regions (Bertacchi, Gruart, et al., 2019). Thus, the patient's unique profile of impaired nonverbal abilities and minimal visual impairment suggests that his non-verbal deficits may reflect both the optic nerve hypoplasia and cerebral visual deficits, including alterations in thalamocortical development, abnormal optic nerve axonal conduction, and impaired visual learning and memory.

Our findings contribute to evidence implicating NR2F1 in the etiology of ASD, similar to prior studies documenting ASD in patients with BBSOAS (Bosch et al., 2014; Chen et al., 2016; Dimassi et al., 2016). The patient also had jaw expansion surgery for micrognathia. Micrognathia and retrognathia have been reported in several patients with BBSOAS (Al-Kateb et al., 2013; Chen et al., 2016; Hino-Fukuyo et al., 
2017; Kaiwar et al., 2017; Park et al., 2019) and Nr2f receptors are important in the development of the vertebrate upper jaw (Barske et al., 2018). We also document otoplasty and bilateral ear cupping in this patient, similar to descriptions of ear abnormalities, including prominent ears, in 16 of 24 (67\%) individuals with BBSOAS.

The patient's sensorimotor impairments suggest weakened modulation of the cerebellum on pontine-brainstem burst cells (Leigh \& Zee, 2006). Slower reaction times implicate cerebellar-thalamofrontal circuits involved in initiating motor output consistent with studies showing impaired motor behaviors in COUP-TFI mutation mice (Tomassy et al., 2010). We also show a deficit of response inhibition suggesting that changes of subcortical-cortical processes may extend to prefrontal-striatal circuits involved in the development of executive functioning.

In summary, we show that a pathogenic truncating NR2F1 variant is associated with a unique profile characterized by ASD, mild dysmorphic features, reduced sensorimotor precision and speed, and executive dysfunction. This patient's unique cognitive profile of superior verbal abilities and reduced nonverbal abilities contrasts with the majority of patients with BBSOAS diagnosed with intellectual disability or developmental delay, suggesting that NR2F1 variants may confer unique risk for multiple cognitive issues and expands the phenotype of BBSOAS.

\section{ACKNOWLEDGMENTS}

Data used in the preparation of this manuscript have been shared in the NIH-supported National Database for Autism Research (NDAR), collection ID 1. The University of Illinois at Chicago Autism Center of Excellence was supported by NICHD/NINDS/NIEHS through P50HD055751 (MWM, SG, EC). Sequencing services were provided by the Center for Inherited Disease Research (CIDR) through X01 HG007235. CIDR is fully funded through a federal contract from the National Institutes of Health to The Johns Hopkins University, contract number HHSN268201200008I. The NICHD provided funding for the U54 Kansas Intellectual and Developmental Disabilities Research Award (HD090216-01). Additional funding was provided by the National Institutes of Mental Health through R01 MH112734-01 (MWM, EB) and K23 MH092696-05 (MWM).

\section{CONFLICT OF INTEREST}

None.

\section{DATA AVAILABILITY STATEMENT}

Data used in the preparation of this manuscript have been shared as NDAR study \#784 (https://doi.org/10.15154/1504186).

\section{SUPPORTING INFORMATION}

Additional supporting information may be found online in the Supporting Information section at the end of this article. 


\section{REFERENCES}

Al-Kateb, H., Shimony, J. S., Vineyard, M., Manwaring, L., Kulkarni, S., \& Shinawi, M. (2013). NR2F1 haploinsufficiency is associated with optic atrophy, dysmorphism and global developmental delay. Am J Med Genet A, 161A(2), 377-381. doi:10.1002/ajmg.a.35650

Aman, M. G., Singh, N. N., Stewart, A. W., \& Field, C. J. (1985). The aberrant behavior checklist: a behavior rating scale for the assessment of treatment effects. Am J Ment Defic, 89(5), 485-491.

American Psychiatric Association. (2000). Diagnositic and statistical manual of mental disorders (4th Ed. Text Revision ed.). Washington, DC: American Psychiatric Pub.

Annett, M. (2004). Hand preference observed in large healthy samples: classification, norms and interpretations of increased non-right-handedness by the right shift theory. Br J Psychol, 95(Pt 3), 339-353. doi:10.1348/0007126041528130

Armentano, M., Chou, S. J., Tomassy, G. S., Leingartner, A., O'Leary, D. D., \& Studer, M. (2007). COUP-TFI regulates the balance of cortical patterning between frontal/motor and sensory areas. Nat Neurosci, 10(10), 1277-1286. doi:10.1038/nn1958

Baron, I. S. (2003). Domains and tests. In Neuropsychological evaluations of the child (pp. 93-106). New York: Oxford.

Barske, L., Rataud, P., Behizad, K., Del Rio, L., Cox, S. G., \& Crump, J. G. (2018). Essential role of Nr2f nuclear receptors in patterning the vertebrate upper jaw. Developmental cell, 44(3), 337-347. e335. doi:https://doi.org/10.1016/j.devcel.2017.12.022

Benedict, H. R. B. (1997). Brief visuospatial memory test-revised. Odessa, FL: Psychological Assessment Resources, Inc.

Bertacchi, M., Gruart, A., Kaimakis, P., Allet, C., Serra, L., Giacobini, P., ... Studer, M. (2019). Mouse Nr2f1 haploinsufficiency unveils new pathological mechanisms of a human optic atrophy syndrome. EMBO Molecular Medicine, 11. https://doi.org/10.15252/emmm.201910291

Bertacchi, M., Parisot, J., \& Studer, M. (2019). The pleiotropic transcriptional regulator COUP-TFI plays multiple roles in neural development and disease. Brain Research, 1705, 75-94. doi:https://doi.org/10.1016/j.brainres.2018.04.024

Bosch, D. G., Boonstra, F. N., Gonzaga-Jauregui, C., Xu, M., de Ligt, J., Jhangiani, S., . . Schaaf, C. P. (2014). NR2F1 mutations cause optic atrophy with intellectual disability. Am J Hum Genet, 94(2), 303-309. doi:10.1016/j.ajhg.2014.01.002

Chen, C. A., Bosch, D. G., Cho, M. T., Rosenfeld, J. A., Shinawi, M., Lewis, R. A., . . Schaaf, C. (2016). The expanding clinical phenotype of Bosch-Boonstra-Schaaf optic atrophy syndrome: 20 new cases and possible genotypephenotype correlations. Genet Med, 18(11), 1143-1150. doi:10.1038/gim.2016.18

Chen, R., Davis, L. K., Guter, S., Wei, Q., Jacob, S., Potter, M. H., . . . Li, B. (2017). Leveraging blood serotonin as an endophenotype to identify de novo and rare variants involved in autism. Mol Autism, 8, 14. doi:10.1186/s13229-017-0130-3

Delis, D. C., Kramer, J. H., Kaplan, E., \& Ober, B. A. (2000). California verbal learning test second edition (CVLT-II). San Antonio, TX: The Psychological Corporation, a Harcourt Assessment Company.

Dimassi, S., Labalme, A., Ville, D., Calender, A., Mignot, C., Boutry-Kryza, N., . . . Lesca, G. (2016). Whole-exome sequencing improves the diagnosis yield in sporadic infantile spasm syndrome. Clin Genet, 89(2), 198-204. doi:10.1111/cge.12636

Hino-Fukuyo, N., Kikuchi, A., Yokoyama, H., linuma, K., Hirose, M., Haginoya, K., ... Kure, S. (2017). Long-term outcome of a 26-year-old woman with west syndrome and an nuclear receptor subfamily 2 group F member 1 gene (NR2F1) mutation. Seizure, 50, 144-146. https://doi.org/10.1016/j.seizure.2017.06.018

Kaiwar, C., Zimmermann, M. T., Ferber, M. J., Niu, Z., Urrutia, R. A., Klee, E. W., \& Babovic-Vuksanovic, D. (2017). Novel NR2F1 variants likely disrupt DNA binding: molecular modeling in two cases, review of published cases, 
genotype-phenotype correlation, and phenotypic expansion of the Bosch-Boonstra-Schaaf optic atrophy syndrome. Cold Spring Harb Mol Case Stud, 3(6). doi:10.1101/mcs.a002162

Leigh, R. J., \& Zee, D. S. (2006). In The Neurology of Eye Movements (Fourth Edition ed., pp. 188-240). New York, NY: Oxford University Press.

Lin, F.-J., Qin, J., Tang, K., Tsai, S. Y., \& Tsai, M.-J. (2011). Coup d'Etat: an orphan takes control. Endocrine reviews, 32(3), 404-421. doi:https://doi.org/10.1210/er.2010-0021

Lord, C., Rutter, M., DiLavore, P. C., Risi, S., Gotham, K., \& Bishop, S. (2012). Autism diagnostic observation schedule, (ADOS-2) modules 1-4. Los Angels, California: Western Psychological Services.

Mosconi, M. W., Kay, M., D'Cruz, A. M., Seidenfeld, A., Guter, S., Stanford, L. D., \& Sweeney, J. A. (2009). Impaired inhibitory control is associated with higher-order repetitive behaviors in autism spectrum disorders. Psychological Medicine, 39(9), 1559-1566. doi:10.1017/S0033291708004984

Park, S. E., Lee, J. S., Lee, S.-T., Kim, H. Y., Han, S.-H., \& Han, J. (2019). Targeted panel sequencing identifies a novel NR2F1 mutations in a patient with Bosch-Boonstra-Schaaf optic atrophy syndrome. Ophthalmic Genetics, 1-3. https://doi.org/10.1080/13816810.2019. 1650074

Reitan, R. M. (1992). Trail making test manual for administration and scoring. Mesa, AZ: Reitan Neuropsychology Laboratory.

Rutter, M., Bailey, A., \& Lord, C. (2003). Social communication questionnaire. Los Angeles: Western Psychological Services.

Rutter, M., Le Couteur, A., \& Lord, C. (2003). Autism Diagnostic Interview, Revised (ADI-R). Los Angeles, CA: Western Psychological Services.

Schmitt, L. M., Ankeny, L. D., Sweeney, J. A., \& Mosconi, M. W. (2016). Inhibitory control processes and the strategies that support them during hand and eye movements. Frontiers in Psychology, 7(1927). doi:10.3389/fpsyg.2016.01927

Shah, A., \& Frith, U. (1993). Why do autistic individuals show superior performance on the block design task? Journal of Child Psychology and Psychiatry, 34(8), 1351-1364. doi:https://doi.org/10.1111/j.14697610.1993.tb02095.x

Sparrow, S. S., Chiccetti, D. V., \& Balla, D. A. (2005). Vineland adaptive behavior scales, 2nd edition. San Antonio: The Psychological Corporation.

Tang, K., Xie, X., Park, J. I., Jamrich, M., Tsai, S., \& Tsai, M. J. (2010). COUP-TFs regulate eye development by controlling factors essential for optic vesicle morphogenesis. Development, 137(5), 725-734. doi:10.1242/dev.040568

Tomassy, G. S., De Leonibus, E., Jabaudon, D., Lodato, S., Alfano, C., Mele, A., . . Studer, M. (2010). Area-specific temporal control of corticospinal motor neuron differentiation by COUP-TFI. Proc Natl Acad Sci U S A, 107(8), 3576-3581. doi:10.1073/pnas.0911792107

Trites, R. (1989). Grooved pegboard test: Royal Ottawa Hospital.

Wechsler, D. (1999). Wechsler abbreviated scale of intelligence. San Antonio: The Psychological Corporation.

Wechsler, D., Coalson, D. L., \& Raiford, S. E. (2008). WAIS-IV: Wechsler adult intelligence scale. San Antonio, TX: Pearson.

Zhou, C., Qiu, Y., Pereira, F. A., Michael, C. C., Tasi, S. Y., \& Tsai, M. J. (1999). The Nuclear Orphan Receptor CoUPTFI Is Required for Differentiation of Subplate Neurons and Guidance of Thalamocortical Axons. Neuron, 24, 847-859. doi:https://doi.org/10.1016/s0896-6273(00)81032-6 
Table 1. Demographic and clinical data for patient, individuals with ASD, and healthy controls

\begin{tabular}{|c|c|c|c|}
\hline Age of patient (years: months) & VIQ & PIQ & VIQ-PIQ SD \\
\hline $3: 2^{\mathrm{a}}$ & 59 & 47 & 1.2 \\
\hline $5: 10^{b}$ & 135 & 76 & 3.9 \\
\hline $8: 2^{c}$ & 140 & 58 & 5.5 \\
\hline $12: 6^{c}$ & 122 & 65 & 3.8 \\
\hline $18: 0^{d}$ & 117 & 62 & 3.7 \\
\hline $23: 00^{e}$ & $141^{f}$ & $63^{g}$ & 5.2 \\
\hline Assessment & $\begin{array}{c}\text { Patient } \\
(\mathrm{N}=1)\end{array}$ & $\begin{array}{c}\text { ASD } \\
(\mathrm{N}=6)\end{array}$ & $\begin{array}{c}\text { Controls } \\
(\mathrm{N}=6)\end{array}$ \\
\hline Full Scale IQ & 90 & $110(13)$ & $110(11)$ \\
\hline Verbal IQ & 141 & $114(23)$ & $106(14)$ \\
\hline Performance IQ & 63 & $105(12)$ & $111(9)$ \\
\hline Age & 23 & $23(2)$ & $26(3)$ \\
\hline \multicolumn{4}{|l|}{ ADOS-2 } \\
\hline Communication & 3 & $3(1)$ & - \\
\hline Social & 5 & $6(2)$ & - \\
\hline Stereotyped behaviors and restricted interests & 1 & $2(1)$ & - \\
\hline \multicolumn{4}{|l|}{ ADI-R } \\
\hline Reciprocal social interaction & 5 & $18(4)$ & - \\
\hline Communication (verbal) & 5 & $12(6)$ & - \\
\hline Restricted, repetitive, and stereotyped behaviors & 4 & $4(2)$ & - \\
\hline \multicolumn{4}{|l|}{ Aberrant Behavior Checklist } \\
\hline Hyperactivity & 9 & $5(1)$ & $5(6)$ \\
\hline Inappropriate Speech & 5 & $2(2)$ & $1(1)$ \\
\hline Irritability & 3 & $5(4)$ & $2(3)$ \\
\hline Lethargy & 6 & $22(8)$ & $6(8)$ \\
\hline Stereotypy & 3 & $1(1)$ & $1(1)$ \\
\hline \multicolumn{4}{|l|}{ Vineland Adaptive Behavior Scales II } \\
\hline Communication & 87 & $77(24)$ & - \\
\hline Daily Living & 68 & $78(13)$ & - \\
\hline Overall adaptive behavior & 75 & $69(15)$ & - \\
\hline
\end{tabular}

\footnotetext{
${ }^{a}$ McCarthy Scales of Children's Abilities. Data reported are t-score, SD of t-score $=10$. ${ }^{b}$ Wechsler preschool and primary scale of intelligence - revised (WPPSI-R). 'Wechsler Intelligence Scale for Children, Third Edition (WISC-III).

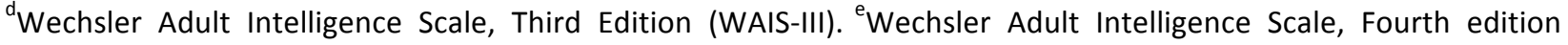
(WAIS-IV). ${ }^{f}$ Verbal Comprehension Index. ${ }^{\mathrm{g}}$ Perceptual Reasoning Index. Data are mean (SD). Scores reported for WPPSI-R, WISC-III, WAIS-III, WAIS-IV, and Vineland Adaptive Behavior Scales II are standard scores (SD = 15). Scores for the Autism Diagnostic Observation Schedule, Second Edition (ADOS-2), Autism Diagnostic Interview-Revised (ADI-R), and Aberrant Behavior Checklist are raw scores. ASD, autism spectrum disorder; VIQ, verbal IQ; PIQ, performance IQ.
} 
Table 2. Sensorimotor task results for patient, individuals with ASD, and healthy controls.

\begin{tabular}{lccc}
\hline & $\begin{array}{c}\text { Patient } \\
(\mathrm{N}=1)\end{array}$ & $\begin{array}{c}\text { ASD } \\
(\mathrm{N}=6)\end{array}$ & $\begin{array}{c}\text { Controls } \\
(\mathrm{N}=6)\end{array}$ \\
$\begin{array}{l}\text { Visually guided saccade } \\
\text { Latency (ms) }\end{array}$ & 214.96 & $237.53(48.29)$ & $207.96(40.01)$ \\
$\quad$ Gain & 0.83 & $0.92(0.05)$ & $0.92(0.07)$ \\
$\begin{array}{l}\text { Antisaccade } \\
\text { Gap }\end{array}$ & & & \\
$\quad$ Latency (ms) & 289.00 & $397.40(84.50)$ & $288.13(68.29)$ \\
$\quad$ Prosaccade errors (\%) & 89.47 & $34.63(31.91)$ & $26.91(19.83)$ \\
$\quad$ Overlap & & & \\
$\quad$ Latency (ms) & 497.33 & $578.90(41.91)$ & $503.23(94.30)$ \\
$\quad$ Prosaccade errors (\%) & 88.89 & $38.72(35.56)$ & $23.21(10.33)$ \\
Oculomotor stop signal task & & & \\
$\quad$ \% correct STOP trials & 6.94 & $64.67(11.30)$ & $77.44(7.16)$ \\
$\quad$ Reaction time slowing (ms) & 10.85 & $80.88(53.13)$ & $152.10(23.04)$ \\
Manual motor stop signal task & & & \\
$\quad$ correct STOP trials & 47.00 & $69.67(14.40)$ & $78.33(7.61)$ \\
Reaction time slowing (ms) & 59.83 & $124.08(33.50)$ & $143.83(37.09)$ \\
\hline
\end{tabular}

Data are mean (SD). ASD, autism spectrum disorder; ms, milliseconds. 


\section{Supplemental Information}

Table S1. Standardized neuropsychological assessment results for patient, individuals with ASD, and healthy controls.

\begin{tabular}{lccc}
\hline & $\begin{array}{c}\text { Patient } \\
(\mathrm{N}=1)\end{array}$ & $\begin{array}{c}\text { ASD } \\
(\mathrm{N}=6)\end{array}$ & $\begin{array}{c}\text { Controls } \\
(\mathrm{N}=6)\end{array}$ \\
\hline Trails A Completion Time (sec) & 38.00 & $35.11(9.06)$ & $22.31(5.60)$ \\
Trails B Completion Time (sec) & 109.00 & $71.83(16.32)$ & $43.15(11.41)$ \\
Finger Tapping & & & \\
$\quad$ Dominant Hand Reaction Time & 58.67 & $44.20(6.35)$ & $42.74(7.36)$ \\
$\quad$ Non-dominant Hand Reaction Time & 44.00 & $41.80(7.21)$ & $39.83(4.76)$ \\
Grooved Pegboard & & & \\
$\quad$ Dominant Hand Reaction Time & 115.00 & $101.07(42.33)$ & $64.55(8.75)$ \\
$\quad$ Non-dominant Hand Reaction Time & 143.00 & $93.74(26.51)$ & $68.49(11.82)$ \\
Annett Handedness Total Score & 11.00 & $6.50(7.29)$ & $10.50(2.81)$ \\
\hline
\end{tabular}

Scores are reported as mean (SD). sec, seconds. For the Annett Handedness total score, a higher score indicates more right handed. 